\title{
"All This is For My Child, For My Family"
}

Family Obligation and Living with HIV/AIDS in China

\section{Yanqiu Rachel Zhou}

\section{OpenEdition}

\section{Journals}

Electronic version

URL: http://journals.openedition.org/chinaperspectives/4770

DOI: $10.4000 /$ chinaperspectives. 4770

ISSN: 1996-4617

\section{Publisher}

Centre d'étude français sur la Chine contemporaine

\section{Printed version}

Date of publication: 1 April 2009

Number of pages: 29-39

ISSN: 2070-3449

\section{Electronic reference}

Yanqiu Rachel Zhou, " "All This is For My Child, For My Family" », China Perspectives [Online], 2009/1 | 2009, Online since 01 April 2011, connection on 28 October 2019. URL : http://

journals.openedition.org/chinaperspectives/4770 ; DOI : 10.4000/chinaperspectives.4770

(C) All rights reserved 


\section{"All This is For My Child,}

For My Family"

Family Obligation and Living with HIV/AIDS in China

YANQIU RACHEL ZHOU

Social discrimination and limited health care resources drive many people living with HIV/AIDS in China to seek help from their own families. This paper, which is based on a qualitative study of the experiences of this population, examines how the notion of family obligation has influenced how these individuals organise various aspects of their daily lives. Viewing family obligation as a matter of reciprocal relationships, a closer look is taken at the ways in which these individuals exercise their autonomy to fulfil those obligations and pursue their moral self despite their health status. The study suggests the significance as well as the limitations of incorporating family support into AIDS interventions in the Chinese context.

A ccording to the Joint United Nations Programme on HIV/AIDS in China, ${ }^{(1)}$ the estimated number of HIV-infected individuals in this country was 700,000 at the end of 2007. Although the prevalence among China's population is not very high (approximately 0.05 per cent), this epidemic shows no signs of abating. In 2007 alone, there were 50,000 new infections in China, and transmission routes included heterosexual transmission (44.7 percent), men who have sex with men (12.2 percent), injection drug users (42 percent), and mother-to-child transmission (1 percent). The Chinese government hopes to keep the number of HIV-infected people below 1.5 million by 2010. ${ }^{(2)}$

Although education campaigns in recent years have improved knowledge of HIV/AIDS in China, it has been, and continues to be, viewed by the public as a disease imbued with such negative meanings as "immorality," "promiscuity," "perversion," "contagiousness," and "death." (3) Stigma associated with this disease and discrimination against HIV-infected people are widespread, inhibiting many from accessing the HIV test and engaging health care despite the availability of such services. ${ }^{(4)}$ Meanwhile, the affordability of medical care has become a salient issue for many Chinese, especially the urban poor and rural residents, since the launch of health care reforms in the 1980s. Research suggests that unaffordability of health care services continues to discourage HIV-infected individuals and their families from seeking services. ${ }^{(5)}$ Confronting limited social and institutional support from the larger society, people with HIV/AIDS may have to seek help from their families. ${ }^{(6)}$
A study of the effects of family support on the lives of HIVinfected individuals in Yunnan Province, for instance, found that in many cases family was the primary source of various forms of assistance, including financial assistance, support in the disclosure processes, routine daily activities, medical assistance, and psychological support. ${ }^{(7)}$ The disclosure

1. The Joint United Nations Programme on HIV/AIDS in China, "Key Data," 2008 http://www.unaids.org.cn/en/index/page.asp?classname=Key+Data\&id=178\&cla $\mathrm{ss}=2$ (accessed 12 December 2008).

2. Ibid.

3. Yanqiu R. Zhou, "'If You Get AIDS? You Have to Endure It Alone': Understanding the social constructions of HIV/AIDS in China," Social Science \& Medicine, vol. 65, n ${ }^{\circ}$ 2, 2007, pp. 284-295; p. 285.

4. For example, see L. Li et al., "Stigmatization and Shame: Consequences of Caring for HIV/AIDS Patients in China," AIDS Care, vol. 19, no 2, 2007, pp. 258-263; El Lieber, et al., "HIV/STD Stigmatization Fears as Health-seeking Barriers in China," AIDS Behaviours, vol. 10, no 5, 2006, pp. 463-471; Hongjie Liu et al., "Understanding Interrelationships Among HIV-Related Stigma, Concern About HIV Infection, and Intent to Disclose HIV Serostatus: A Pretest-Posttest Study in a Rural Area of Eastern China," AIDS Patient Care and STDs, vol. 20, no 2, 2006, pp. 133142; Jie Xu et al., "AIDS Patient Care and STDs," AIDS Patient Care and STDs, vol. 21, no 11, 2007, pp. 787-798; Yanqiu R. Zhou, "Help-seeking in a Context of AIDS Stigma: Understanding the Health Care Needs of People with HIV/AIDS in China," Health \& Social Care in the Community, in press.

5. J. Xu et al., "Economic Stress and HIV-associated Health Care Utilization in a Rural Region of China: A Qualitative Study," AIDS Patient Care and STDs, vol. 21, no 11, 2007, pp.11787-98; Han-Zhu Qian et al., "Co-infection with HIV and Hepatitis C Virus in Former Plasma/blood Donors: Challenge for Patient Care in Rural China," AIDS, vol. 20, no 10, 2006, pp. 1429-1435.

6. Jun-qing Wu et al., "Family Status and Dilemma of HIV Positive Subjects," Journal of Reproduction and Contraception, vol. 18, no 2, 2007, pp.127-132; Yanqiu R. Zhou, "Endangered Womanhood: Women's Experiences with HIV/AIDS in China," Qualitative Health Research, 18, 2008, pp.1116-1126.

7. Li Li et al., "Understanding Family Support for People Living with HIV/AIDS in Yunnan, China," AIDS and Behavior, vol. 10, no 5, 2006, pp. 509-517. 
required to access family support tends to be a difficult decision for the HIV-infected, however, because it may lead to negative reactions from their families, and have adverse impacts on family relationships, resulting in various pressures or burdens (e.g., psychological and financial) for their families, and/or endangering their desired identities (e.g., as a breadwinner or as an honourable family member) in the context of Chinese culture. ${ }^{(8)}$

Such studies on family impact on people with HIV/AIDS in China have enriched our understanding of the role of family in shaping these individuals' capacities to respond to this epidemic by mobilising non-institutional resources. In these studies, however, people with HIV/AIDS were largely depicted as passive "victims" who required unilateral support from their families; little attention was given to the autonomy these individuals exercised within their families, the family being an important social institution founded on the principle of reciprocity (i.e., fulfilment of mutual obligations) in Chinese culture. ${ }^{(9)}$ Some studies have discovered that when AIDS stigma in China is extended from HIV-infected individuals to their families, for example, these individuals would consciously avoid disclosure and/or accessing health care in order to protect their families from that stigma and discrimination. ${ }^{(10)}$ In other words, the great need of HIV-infected individuals for family support may co-exist with their strong desire to reduce the impact of the disease on their families. It is nonetheless unclear, for example, how the notion of family obligation has affected HIV-infected individuals' understanding of their need for support and their actual process of help-seeking.

Although different forms of "family obligation" are found in various cultures, ${ }^{(11)}$ this notion, as a cultural ideology integral to Confucianism, has exerted considerable influence on every aspect of Chinese family life over time. The modernisation process in China has not yet produced an institutional welfare system capable of replacing conventional, familybased support networks in a satisfactory manner. ${ }^{(12)}$ Kinshipbased family as the fundamental social unit in Chinese society has traditionally performed two major functions: internally, it is a system founded on the hierarchy (based on, for example, gender and age) and mutual obligations of family members, and responsible for ensuring its members' welfare (e.g., education, health, finance, and care); externally, it presents a family image that meets socially desirable standards. ${ }^{(1)}$ For instance, filial piety, the most important family obligation, reflects the reciprocity of the family members' moral duties: while parents have responsibility to raise children, children also have the obligation to take care of their elderly parents through such intentions and behaviours as loving them, respecting them, continuing the family line, protecting them, and caring for them. ${ }^{(14)}$ Despite the increasing impact of modernisation and Westernisation on Chinese culture, these obligations are still endorsed by the younger generation in China and by Chinese adolescents in Western countries. ${ }^{(15)}$ In this cultural system, individual interests often interweave with family interests; more important, an individual's personhood or moral self is influenced by his/her ability to fulfil those role requirements for the sake of family interests. Failure to fulfil family obligations or violating the cycle of reciprocal duties (e.g., elderly parents caring for adult children) would not only result in feelings of guilt and shame, but also jeopardise one's identity in the larger society. ${ }^{(16)}$ In this light, HIV infection has posed multiple threats to the families affected by it: within the family, HIV-infect-

8. For example, see Dorothy Chin et al., "Disclosure of HIV Infection among Asian/Pacific Islander American Women: Cultural Stigma and Support," Cultural Diversity and Ethnic Minority Psychology, vol. 5, no 3, 1999, pp. 222-235; Guoping Ji et al., "The impact of HIV/AIDS on families and children - a study in China," AIDS, vol. 21, no Suppl 8, 2007, pp.S157-S161; Li Li et al., "Stigmatization and Shame," art. cit.; Yanqiu R. Zhou, "Endangered Womanhood," art. cit.

9. Eleanor E. Holroyd, "Chinese Cultural Influences on Parental Caregiving Obligations toward Children with Disabilities," Qualitative Health Research, vol. 13, no 1, 2003, pp. 4-19.

10. Li Li et al., "Understanding Family Support" art. cit.; Yanqiu R. Zhou, "Homosexuality, Seropositivity, and Family Obligations: Perspectives of HIV-infected Men Who Have Sex with Men in China," Culture, Health and Sexuality, vol. 8, no 6, 2006, pp. 487-500. Yanqiu R. Zhou, "If You Get AIDS? You Have to Endure It Alone': Understanding the Social Constructions of HIV/AIDS in China," op.cit.

11. For example, the strong sense of familial duty is also reported in Indian, Filipino, Latin American, and African American families. See Andrew J. Fuligni, et al., "Family Obligation and the Transition to Young Adulthood," Developmental Psychology, vol. 38, no 5, 2002, pp.856-868; Harriette P. McAdo0, Black Families (4th ed.), Thousand Oaks, CA, SAGE, 2007; A.J. Fuligni, et al., "Family Obligation and the Academic Motivation of Young Children From Immigrant Families," in Catherine R. Cooper et al. (eds), Developmental pathways through middle childhood: Rethinking contexts and diversity as resources, Mahwah, N.J., Lawrence Erlbaum Associates, 2005, pp. 262-282.

12. For example, the rigid population registration (hukou) system currently excludes rural residents and migrants from the Chinese urban social welfare system. See Allen Smart et al., "Local Citizenship: Welfare Reform, Urban/rural Status, and Exclusion in China," Environment and Planning, vol. A33, no 10, 2001, pp. 1853 - 1869; Elisabeth Croll, "Social Welfare Reform: Trends and Tensions," China Quarterly, vol.159, 1999, pp. 684-699.

13. Francis Fukuyama, "Confucianism and Democracy," Journal of Democracy, vol. 6, no 2, 1995, pp. 20-33.

14. Eleanor E. Holroyd, "Hong Kong Chinese Daughters' Intergenerational Caregiving Obligations: A Cultural Model Approach," Social Science \& Medicine, vol. 53, no 9, 2001, pp. 1125-1134; Thomas K. S. Wong et al., "Holism and Caring: Nursing in the Chinese Health Care Culture," Holistic Nursing Practice, vol. 15, no 1, 2000, pp. 12-21.

15. Andrew J. Fuligni et al., "The Impact of Family Obligation on the Daily Activities and Psychological Well-Being of Chinese American Adolescents," Child Development, 2003, vol. 73, no 1, pp. 302-314; Xiaodong Yue et al., "Filial Obligations and Expectations in China: Current Views from Young and Old People in Beijing," Asian Journal of Social Psychology, vol. 2, no 2, 1999, pp. 215-226.

16. Olwen A. Bedford, "The Individual Experience of Guilt and Shame in Chinese Culture," Culture \& Psychology, vol. 10, no 1, 2004, pp. 29-52; Eleanor E. Holroyd, "Chinese Cultural Influences," art. cit.; Lawrence Hsin Yang et al., "'Face' and the Embodiment of Stigma in China: The Cases of Schizophrenia and AIDS," Social Science \& Medicine, vol. 67, no 3, 2008, pp. 398-408. 
ed individuals may be unable to fulfil their obligations to others, and may request extra help from them; outside it, AIDS stigma may compromise the reputation or "face" of the family, and lead to the whole family's stigmatisation. Given that family is among the few accessible and reliable support resources for people with HIV/AIDS in China, it is worth exploring the interactions between the disease and the notion of family obligation, and how such interactions affect the experience of those who live with the disease.

The objective of this paper, therefore, as part of a research project on the experience of people living with HIV/AIDS in China, is to explore how the notion of family obligation has influenced how these individuals organise various aspects of their daily lives, including decision-making on disclosure, making sense of their relationships with family, and their development of strategies to minimise the impact of this disease on their families. Viewing family obligation as a matter of reciprocal relationships, a closer look is taken at the ways in which these individuals exercise their autonomy to fulfil their family obligations and to pursue their moral self despite their health status. Based on the main themes emerging from data analysis, this paper presents the results relating to the role of family obligation in shaping the postdiagnosis experience of people with HIV/AIDS. These results also lay a foundation for discussing the significance as well as the limitations of incorporating family support into AIDS interventions in the Chinese socio-cultural context.

\section{Methods}

The core purpose of this study is to understand the illness experience of Chinese HIV-infected individuals from their own perspectives. To this end, a phenomenological approach, informed by a number of authors, ${ }^{(17)}$ was adopted. First, the phenomenological approach aims to describe, understand, and investigate the meanings of lived experiences. It recognises that HIV-infected individuals are able to articulate the meaning of their experience of living with HIV/AIDS within their own contexts. Second, the phenomenological approach attempts to understand an empirical matter or phenomenon from the perspective of those who experience it. Viewing individuals' experiences and perceptions as positional and intentional, this approach also allows an examination of such experiences in a way that is not constrained by researcher preconceptions. Third, the phenomenological approach recognises the importance of individuals' reflective descriptions of experience, through which the researcher is able to gain access to the meaning of their experience.
The data for this study were collected through individual, face-to-face, semi-structured, in-depth interviews with 21 adults living with HIV/AIDS in a metropolitan city in northern China in 2004. Four of the 21 were recruited through local social and health networks (e.g., hospitals and AIDS non-governmental organisations), one was directly recruited by the researcher from an AIDS-related conference, and the other 16 participants were recruited through snowball sampling based on personal referrals by the participants interviewed. Written, informed consents were obtained from all participants before the interviews. Interviews with 15 were audiotaped, and detailed notes were taken with the remainder, in accordance with their permission and preferences.

The interview guide included several general prompts to ensure that the interviews maintained a focus, and that major themes of interest were explored. After introducing each participant to the research project, the researcher suggested that the participant organise her/his storyline according to her/his rationale (rather than the researcher's) so as to facilitate a participant-led discussion, though most still preferred sharing their experiences by answering the researcher's interview questions. Specifically, the researcher asked these participants questions about their experience of living with HIV/AIDS, their understanding of such experience, their self-perceptions, and the strategies they used to facilitate living with HIV/AIDS. They were also asked about their understanding of the terms "HIV/AIDS" and "people living with HIV/AIDS" in relation to their illness experience.

Participants were interviewed in Mandarin by the researcher, a native Mandarin speaker. The length of each interview ranged from two to three hours, including the time for informed consent, the interview itself, and collection of demographic information. Although numerous meetings/interviews with participants is desirable in the phenomenological approach, it turned out to be impossible in this study because the participants were unable to commit more time and energy for a number of reasons, including their employment and/or health status, inasmuch as HIV-infected participants perceived that meeting with the researcher more than one time would increase the odds of a breach of their secret, and/or

17. For example, see John W. Creswell, Qualitative inquiry and research design: Choosing among five traditions, London, Sage, 1998; Maurice Merleau-Ponty, "The Primacy of Perception and Its Philosophical Consequences," in Dermot Moran and Tim Mooney (eds), The Phenomenology Reader, London, Routledge, 2002, pp. 436-460; Maurice Merleau-Ponty, "The Body as Object and Mechanistic Physiology," in Dermot Moran and Tim Mooney (eds), The Phenomenology Reader, London, Routledge, 2002, pp. 427-435; Clark Moustakas, Phenomenological research methods, Thousand Oaks, Sage, 1994. 
the financial and physical challenges that travelling for the interview presented for most of them.

Of the 21 participants, 15 were men and six were women. Their ages ranged from 23 to 46, and education levels were divided among university $(2 / 11)$, college $(2 / 11)$, senior high school $(5 / 21)$, and junior high school $(2 / 11)$ graduates. With regard to relationship status, seven participants were married, five were living with their partners, three were divorced, three had been widowed by the death of their HIV-infected husbands, and three were currently single and had never married. Their infection modes were divided among "blood transfusion or blood products" (2/21), "commercial blood donation" (1/21), "heterosexual behaviours"(4/21), "men who have sex with men" (11/21), and "not sure" (3/21). At the time of interview, the length of their HIV diagnosis was 0.9 year ( 11 months) to 9.6 years (115 months), with an average of 3.9 years (46.6 months). The audiotaped interviews were transcribed verbatim in Chinese. The researcher read through the texts of all transcripts and interview notes as constituting the full descriptions of participants' experiences, and then assigned tentative category labels (e.g., "beliefs about HIV/AIDS" and "self-perception") to the unique or discrete statements of participants. Statements with similar category labels were later grouped into clusters using $\mathrm{NV}$ ivo, a software program for qualitative study, and careful attention was paid to the diversity of perspectives presented. Themes emerged in the process of coding, presenting the meanings of the reported experiences. Based on the data analysis, the researcher was able to develop a comprehensive synthesis of these participants' understanding of HIV/AIDS. To avoid the loss of nuance within original narratives, the transcribed data were not translated into English until the stage of report writing. Pseudonyms have been used to protect participants' identities.

\section{Results}

\section{Secret-keeping within family and for family: "No good can come from letting them know"}

Despite their expressed need for social support, each participant in this study made a very careful decision about disclosure after weighing its potential gains and losses, influenced by such factors as mode of infection, concern about secondary transmission, and intention to avoid upsetting family members. Those in a relationship (i.e., married or living with a partner) often found telling the truth to their partners unavoid- able in order to prevent the latter's exposure to HIV. Such disclosure, though not mandatory, was often encouraged by health workers or authorities. Participants infected through "innocent" modes (e.g., blood donation and blood transfusion) presented comparatively few difficulties in disclosure to their families. Mr. Zhuang, for instance, did so immediately (to his wife, mother, and sisters and their families) after his diagnosis, primarily because he was infected through commercial blood donation rather than his "own fault." Such openness was rare among those whose infection modes were viewed as "guilty" under the traditional moral gaze. $\mathrm{Mr}$. $\mathrm{Mu}$, a man infected through engaging in sex with a woman other than his fiancée, struggled for a year before finally disclosing it to her, and four years after his diagnosis he still hadn't told his parents or his only brother. Participants' timely disclosure to their partners could have precluded putting the partners at further risk, while procrastination, in some cases possibly related to a delayed HIV test, often delayed their partners' becoming aware of their own health status and getting medical attention.

Concern for elderly parents and/or young children was also an important factor influencing participants in their decision on disclosure. Many chose not to disclose to their parents because "they are too old to bear such a bad news," "they already have much to worry about," or "no good can come from letting them know about this." Mr. Ge, for instance, told his mother about his sexual orientation, but didn't dare tell her about his seropositive status, because he doubted her ability to endure another shock. Mr. Qin decided to hide his secrets (being a gay man and being seropositive) forever from his parents and grandmother, because disclosure might have further compromised their already delicate health. Mr. $\mathrm{Mu}$ worried that his disclosure would further burden his parents and distract their attention from his younger brother, who was also in poor health. Consideration for family was central in the process of these participants' decision-making on disclosure, as illustrated by Mr. Jian's scrutiny:

The most painful thing is that I feel so sorry for my family. I just graduated from college, and haven't had a chance to repay them yet. But now I have been pushed to the edge of death myself. Some people have encouraged me to disclose it to my family. But if I did so, I would feel guiltier, I could not forgive myself. [If I told them,] perhaps my psychological pressure would be lighter. But why should I let my family bear a burden that is my own fault?! ... Even if I told them, they couldn't solve the problem, but 
only feel pressured. Some people think the pressure can be lighter if it is shared with others. I don't think so. I think if I shared it with my family, it still would be a pressure [for them]. Because they love me, the weight of the pressure they have would be similar to mine.

Nevertheless, a couple of participants did disclose their seropositive status to their parents, each for their own reasons and dictated by their circumstances. Mr. Pin, a gay man in his late 20s, did so because he didn't want his parents to waste money arranging his wedding ceremony, which was eventually cancelled. Ms. Qian, as well, used the disclosure as a way to stop her parents pushing her to marry. Although disclosure released both participants from the pressure of marriage, it also increased their guilt at being unable to have offspring and continue the family line, which they viewed as a violation against the norm of filial piety. Meanwhile, nine out of 11 participants with children didn't disclose their health status to them. The only exceptions were Mrs. Xiaofen and Mrs. Yin: the former told her daughter, because the girl was also HIV positive and had already begun antiretroviral drugs; the seropositive status of the latter was inadvertently disclosed by health workers in her home town. A couple of participants, who happened to be those with "innocent" infection modes, also mentioned that they might disclose the truth when their children were older and thus "may be able to appropriately understand it."

Participants who intended to hide their "secret" from their families explained their health status or withdrawal from physical contact by strategically claiming, sometimes with the collaboration of other family members, that they had other diseases. For instance, Mr. Han told his son and other relatives that he had hepatitis $B$ and was thus required to eat separately. Living with his parents-in-law, Mr. Mu and his wife always cooperated in pretending that everything was fine, especially when he was very sick. Similarly, when Mr. Yu was not well, his elder brother would explain to their father that Mr. Yu "had a bad flu."

Due to the pervasive fear of AIDS in Chinese society, secret-keeping outside the family was a common strategy adopted by participants to protect themselves and their families from discrimination and to maintain a "normal" life. Although free antiretroviral drugs had became available in some participants' home towns where their hukou (i.e., their household-registration based identity) were registered, they hesitated to return there to take advantage of the policy because the close-knit small-town communities jeopardised their confidentiality and thus threatened stigma and shame for families members still living there. For this reason, Mrs. $\mathrm{Xiu}$, a self-employed migrant worker and single mother, postponed availing herself of the free drugs in her home town until she ran out of options financially. Mrs. Yin and her family were also unable to go back, given that returning would increase the stigma borne by her father's family in the village. The AIDS stigma also prevented Mrs. Yin from sending her husband to an AIDS-specific hospital in time, because she feared that doing so might disclose his health status to her relatives and home town acquaintances in this metropolitan city and result in discrimination toward their children. Such caution also applied to the city's native residents, as explained by Mr. Han, a man who previously worked at an AIDS NGO:

Every morning I got up for work, my son didn't know where I was going. I didn't tell him...I couldn't tell my relatives or friends that I was working there, working for people with HIV/AIDS... Telling them this is equivalent to telling them that I have HIV...This [i.e., not telling] is very necessary; otherwise, it would have been impossible for me to live like a normal person for the past four years... If your relatives, friends, and neighbours knew you are a person with HIV ... your family would not be allowed to live in the same place, you couldn't contact your relatives or friends as you normally do... So we have to protect ourselves.

Hiding one's seropositive status from family members, however, also means maintaining a "normal" role at home. Saying that he was spending "200 per cent of [his] energy" on his family, for instance, Mr. Yu was still doing his best to perform various family chores, such as renovating their apartment and taking his daughter and mother to the doctor. When Mr. Mu's father was hospitalised, Mr. Mu spent nights sitting beside him on a folding chair, just as a "healthy" son should do, even though he was himself already "too weak to move from that chair."

\section{Family remains the priority: "All this is for my child, for my family"}

As a way to identify their relationship changes, participants were asked to rank the perceived importance of their significant others before and after their HIV diagnoses. Their blood families, including parents and/or children, were always ranked as the most significant others, regardless of 


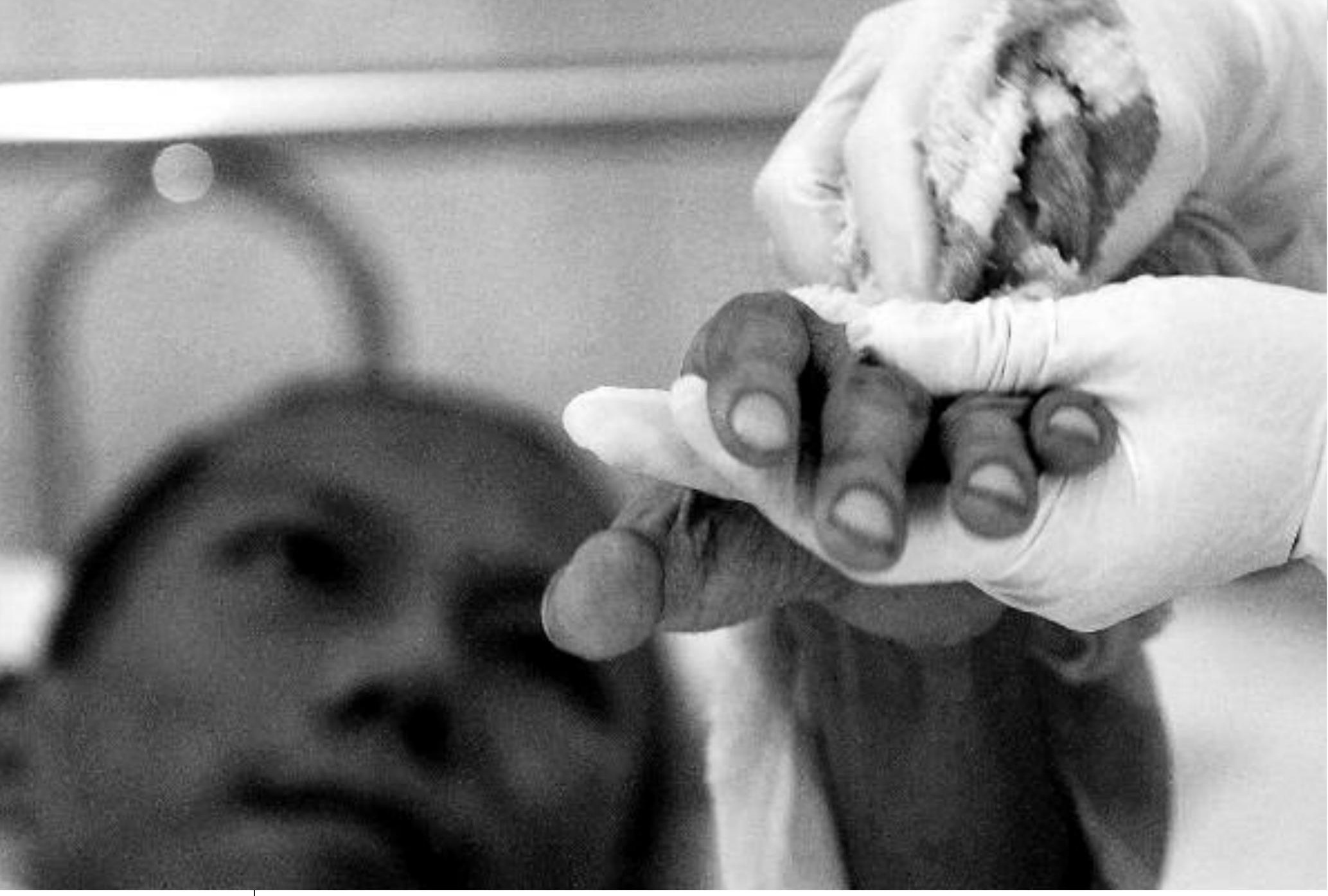

An unidentified AIDS patient watching a nurse cleaning his fingers, at the No. 8 People's hospital in Guangzhou, southern China's Guangdong province. ๑ AFP

the latter's knowledge of or attitude toward their seropositive status, but the perceived importance of their spouses/partners and friends was often determined by their support for the participants. Participants' unconditional love for their parents and/or children is consistent with Chinese traditional norms such as "filial piety" and "parenthood," but was complicated by their HIV infection.

Participants commonly reported a better or closer relationship with their parents than before their diagnosis. Feeling unable to be as filial as a "healthy" person could be, or feeling obliged to be more filial due to their "imminent death," they tended to express more care toward their parents by spending more time with them, communicating with them more often, and being more sensitive to their feelings. Despite her financial difficulties, for example, Ms. Lin, an unemployed migrant worker, tried to send various confections from this city to her parents in her home town, which she described as the only way she could afford to show her filial piety. Likewise, Mr. Jian postponed accessing antiretroviral drugs in order to be able to send money home. Viewing this as "fulfilling a duty for parents," he explained, "They brought me up, so I should take care of them when they get old. No matter how difficult it is, I should fulfil this duty." To some degree, HIV infection had pushed participants to think of their obligations to parents in a more passionate way, as illustrated by the following quotes:

[After my diagnosis,] I thought I should go back home to see my family. Although my health was okay then, I didn't know how long I could live or whether I would ever have another chance to go home. ...When I was at home, I followed my mother around, just like a little child... I asked her things about my family, my village, and many things from the past. I felt I might have little opportunity to ever hear those things again. ... I was worried that I might not be able to go home again. [Interview with Mr. Jian]

When I phone my mother now, I explicitly tell her, "I really miss you! I love you so much!" I didn't say these words before, [although] I have always cared about them, like I've sent them money to buy the 
apartment and to improve the quality of their life. ...In the past I was not tactful: I just said what I wanted to say, whether they liked it or not. Now I have become more tactful and sensitive, I say things with care so that they will feel comfortable about accepting it...But I think what I've done is not enough. I am so envious of those who can go home often to show their filial piety... What I can do now is take good care of my health so that I can have more time to show my filial piety to my parents. [Interview with Mr. Qin]

Although most parents did not disclose their seropositive status to their children, some perceived that their relationships with their children had also become closer than before their HIV diagnosis. Fearing that their infection would separate them from their children forever, parents consciously spent more time and developed closer bonds with them. Mrs. Xiu, for example, described how after his diagnosis her late husband had tried to take every opportunity to be with their son:

My husband loved our son so much. I would say he even spoiled the child... When he learned he had this disease, he knew he had no time left. Ah, he cried whenever he saw him: No time any more! No more chances! Later, he couldn't get up from the bed, so he asked the child to play beside his bed. [Chuckle] But the boy got bored, and asked him: "Dad, can I go outside to play for a while?" His dad said: "One moment, just hold on for one moment, let me have another look at you!" It was so sad... like parting forever!

Similarly, Mrs. Yue deliberately spent more time with her seven-year-old son so as to leave him with a deep memory of her, because he had been so young when his father died that he had no memory of him: "So when my son grows up, he will remember that he was loved by his good mother, and then he may not get that feeling of being helpless." Meanwhile, some participants started to train their children in order to prepare them as well as possible for the time when they would face the world alone. They cultivated their children's good habits, their ability to think and act independently, and their resilience. For instance, Mr. Guogiang was energetically critical of his daughter's "weaknesses" because he wanted her to experience frustration, "so that she will know the world is not all beautiful, and she won't be overwhelmed when it frustrates her."
In the interests of children and/or family, as well, four wives of six participants who had engaged in same-sex practices stayed in their marriages after learning of their husband's sexual preferences, and also played a supportive role in their husbands' post-diagnosis lives. After his disclosure, for instance, neither Mr. Han nor his wife wanted to divorce, because they didn't want to give their son a broken family: "Being parents means we have the responsibility to carry on this family... to contribute to our child's future." Appreciative of their wives' support, and/or feeling guilty about their HIV infection and its consequences for their families, these men withdrew from same-sex practices in order to maintain their marriages and keep their families intact. Viewing their current marriages as "superficial" (i.e., as excluding sex), they yet presented little difficulty in justifying their "sacrifice." As Mr. Yu commented, "All this is for my child, for my family."

\section{Situating self in the context of obligation: "Life or death becomes less important after you fulfil family obligations"}

HIV infection tremendously affected participants' employment status due to their health status, the nature of their work (e.g., they were in the food industry, or it was physically demanding), or disclosure in the working unit of their seropositive status. Of the 21 participants, only 13 had jobs, and of those 13,11 changed employers after their diagnosis. China's economic structure meant that some participants had difficulty finding jobs because of their inadequate educational background or lack of skills, despite their strong desire to be re-employed. For many participants, losing their job meant loss not only of income, but also of employmentbased social and health insurance. It also had an adverse impact on their self-image. For example, Mr. Yu, a man who had been good at his job, felt that his inability to continue working had damaged his self-worth in the larger society and his traditional gendered role as "breadwinner" at home.

Despite their strong intention to be self-sufficient, financial support from their families, including their extended families, became the major and relatively stable source of income, especially for those who had started medical treatment. After Mr. Wuyi's first physical collapse about four years earlier, for instance, he and his partner, Ms. Lin, had become financially dependant on his siblings for medical treatment and daily necessities. In addition to his part-time job, Mr. Zhuang received financial assistance from his four sisters on a monthly basis so as to be able to support his four- 
person family, although his sisters were themselves impoverished migrant workers. He described it thus:

Each of my [four] sisters gives me 300 yuan every month, so it is 1,200 yuan. My monthly medication costs 1,300 yuan. But we also have to eat and pay the rent and pay for public transit to work. If my sisters didn't give me money, I don't know how we could live with my 1,000 yuan salary! It is very hard for my sisters to give me that money every month: they are all migrant workers, and can only earn a few hundred bucks a month, and they have children, too... Especially my third sister, her financial situation is very difficult. Sometimes, she didn't have money to give me, and she was so sad...I feel sad too, because I am unable to support myself.

Losing the support of her in-laws after her husband died of AIDS, Mrs. Xiu, a single mother and migrant worker, had to make a living alone in this city. Her slender earnings made raising her son impossible in that metropolis, so she sent him back to her parents in her home town, where AIDS stigma meant she couldn't visit him often. Although pained by her inability to care for her son, Mrs. Xiu admitted, "It's good enough that I am taking care of myself."

Meanwhile, participants' need for care became salient, especially after they developed symptoms of AIDS. With the limited systematic resources in China, caregiving responsibilities were again borne by these participants' families, in particular by their female members. Most married men in this study reported that their wives voluntarily assumed the role of primary caregiver after learning of their HIV infection. Women undertook multiple caring tasks to maintain their partners' daily functions, such as bathing, cooking, laundry, administering medicine, and hospitalisation. Mr. Han described how his wife cared for him even after being informed of his homosexual preference: "When I was hospitalised, I had catheters in my upper and lower body. Only my wife could take care of me in that kind of situation; no one but my wife could provide such intimate care."

Internalising such gendered obligations, some women in this study even viewed caring for their partners as integral to their own psychological or emotional needs. For instance, Mrs. Yue, a highly educated woman, was certain that she would be taking care of her husband had he survived, because "taking care of him would be like meeting my own psychological need; besides, it's a habit." Yet prioritising partners' care needs over their own threatened to overbur- den them to the detriment of their own health, as well as instigating internal conflicts (e.g., traditional "womanhood" versus their own needs for care) that could engender feelings of guilt. In addition to HIV-infected women in relationships, other women, including mothers and daughters, had to take on the role of caregiver when other support sources were unavailable. For instance, Mrs. Xiaofen's mother had been looking after her and her HIV-infected daughter since Mrs. Xiaofen's health had deteriorated. After Mrs. Yu's parents passed away, her aunt had been helping her look after her son when necessary. Meanwhile, HIV-infected mothers commonly conveyed their deep concerns for the future predicament of their children when the mothers entered the last stage of AIDS and after they died.

Although acceptance and love from family, especially parents, was greatly appreciated by participants, such support also created a conflict between their strong need for family support and their deep sense of guilt for burdening their families. For instance, Mr. Guo, a man in his late 40s, was emotionally overwhelmed when he talked about the support of his father: "Even now, he still says to my sister: 'Be thrifty, just in case you brother will need the money... Without the support of my father, my family, it is definitely unimaginable that I could have lived till today." For his part, Mr. Guo always tried to present a "healthy" image at home, so as to comfort his father:

When I was sick, such as having diarrhoea and fever, I would take the medications furtively. I would not let him know, and I pretended I was well. I always control myself so that he won't realise I am sick. Otherwise, he would worry greatly. The only way he will find out I am sick is if I am too sick to pretend. The rest of the time, I try my best to pretend I am well [in front of him].

After learning of her seropositive status, Ms. Qian's parents asked her to stop sending them money. Her appreciation of her parents' understanding was interwoven with shame, in that "I brought them no happiness, only worries." Ms. Qian's current plan, as an attempt to compensate, was to earn more money in the future so that she could afford to have her mother and her sisters live with her in the city, which is often viewed by rural migrant workers as a way of fulfilling obligations of filial piety. HIV infection had also transformed the mentality of Mr. Ge, a man his early 20s, from that of a carefree boy to one of an adult worried about his parents' future: he had been working harder to pay off 
his parents' apartment mortgage before his health deteriorated. Proud of fulfilling his obligation to his parents, he commented, "It would be regrettable if one couldn't fulfil one's responsibility to others."

Worrying that he would be unable to care for his elderly mother for the rest of her life, Mr. Guogiang was very conflicted about her devotion: "The more she loves me, the more pain I feel. If she treated me badly or if she neglected me, I might feel less guilty." Likewise, Mrs. Yue was always remorseful when her father expressed concern about her health and her future, because "everyone else is able to create a better life for their parents, but I can't." For the same reason, some participants hoped that their last stage of life could be as short as possible so that it would not burden anyone with care and medical costs. Viewing "wasting" his family's money on efforts to rescue him as "meaningless" and "immoral," Mr. Guogiang explained, "What is the point of living a couple more years? The expense of keeping you alive would put your family in financial difficulty, and then they have to pay off the debt for you even after you die. So what is the point, just to draw another breath?!" Many participants perceived life or death as secondary to family obligations: in their words, "Life or death is less important after you fulfil family obligations."

The possibility of dying before their parents also greatly pressured participants. Feeling uncertain about his longevity, Mr. Guogiang said he had a strange wish that his parents could die before he did, so that they would not need to experience the enormous grief of his death in their old age. Being unable to fulfil filial piety as "healthy" people do, some participants saw "being alive" as the only way to repay their elderly parents, though some perceived death as a relief because of such difficulties as financial hardship, social discrimination, and/or physical pain, as illustrated by the narrative below:

When I didn't feel well, I also asked myself why I had to remain alive when I was so tired... Some doctors [once] said to me, "Would you ... rather your mother send you off [i.e., die before your mother]?!' My mother is my constant concern. So later I told myself that I surely could not have any accident - losing me would be a great blow to my mother. No matter what my health status is now, if I still could stand before her, if she knew that I was still alive, I think this would be good enough. Now I don't have the ability to repay her or bring her a better life, but it is good enough if I can remain alive. [Interview with Mr. Jian]

\section{Discussion}

The results of this study suggest that family obligation in the context of HIV/AIDS in China is not a unilateral cultural concept defined solely by the family's support for their HIVinfected members, but a strategic mechanism that imposes reciprocal duties on all family members, and profoundly influences their ability to collectively and collaboratively respond to this disease in the Chinese social, cultural, and economic contexts.

Consistent with earlier studies, ${ }^{(18)}$ this study indicates that people with HIV/AIDS face various barriers (e.g., the cost of health care and program eligibility criteria) in their attempts to access institutional resources such as health insurance and social welfare, and that AIDS stigma and social discrimination have attenuated the social support available to them, thus increasing the importance of the family for meeting their salient needs for psychological support, financial assistance, and care. Although disclosure of seropositive status to one's family may function as the first step in accessing family support, participants' decision-making on disclosure was also affected by their concerns over family interests: that is, disclosure could also have a negative impact (e.g., fear, shame, and psychological burden) on their families and on family relations, given that in Chinese society stigma applies not only to the individual, but also to the family. ${ }^{(19)}$ As they internalise the AIDS stigma of the larger society, meanwhile, affected families may reject their HIV-infected members and refuse to support them, thus intensifying their isolation. The non-disclosure by participants in this study should thus be understood as not only a result of social discrimination, but also as a consciously developed strategy of stigma reduction for both themselves and their families, and of protecting their "normal" lives from dramatic change in family relations and living environment. At the same time, non-disclosure within the family may mean the loss of their most important support resource, and one that is crucial to their post-diagnosis lives, given the scarcity of external support.

Regardless of whether family members knew about their HIV infection, however, the disease substantially changed participants' relationships with their families and themselves.

18. For example, see Li Li et al., "Understanding Family Support," art. cit.; Jun-qing Wu et al., "Family Status and Dilemma," art. cit:; Yanqiu R. Zhou, "Homosexuality, Seropositivity, and Family Obligations," art. cit:; Yanqiu R. Zhou, "Endangered Womanhood," art. cit.

19. Arthur Kleinma et al., "The Social Course of Epilepsy: Chronic IIIness as Social Experience in Interior China," Social Science \& Medicine, vol. 40, no10, 1995, pp.1319-1330; Li Li et al., "Stigmatization and Shame," art. cit. 
Their ability to fulfil filial piety toward their parents was constrained by their stigmatised identity, deteriorated health, gradual loss of self sufficiency, and ultimately, their premature death. Their failure to make their parents proud or happy and to care for them also interrupted the cycle of reciprocal duties within the family. The guilt at being "unfilial" among those who had not married because of their sexual orientation or HIV infection was exacerbated by their inability to carry on the family line. Meanwhile, their decreased financial and physical ability to care for their children and the possibility of leaving them behind undermined some participants' aspirations to live up to the desired social standards of "good parents." Having little to give in return for the financial assistance and care they were receiving from other family members, including spouse, siblings, and relatives, also adversely affected their perceptions of self and their self-worth, which in Chinese culture are largely defined by one's acceptance and fulfilment of moral responsibilities toward others. ${ }^{(20)}$ Their infection had more or less alienated participants from the reciprocal moral duties of family members, and transformed them into a sole receiver of such obligations. Consequently they often experienced internal conflicts and feelings of endangered personhood.

While constraining their ability to fulfil family obligations, however, HIV infection never reduced participants' intention to do so; rather, the imminence of their death made that intention much stronger than before. With limited access to concrete resources (e.g., income and caring labour), participants in this study tended to fulfil their family obligations in non-material and symbolic ways, such as spending more time with parents and/or children and explicit expression of love. Although they were unable to substantially contribute to family welfare as a "healthy" person could, they tried their best to reduce HIV-related burdens (e.g., financial assistance, caregiving, psychological pressure, and emotional shock) on their families through maintaining self-sufficiency, postponing access to medical treatment, staying alive, and secret-keeping. For these participants, minimising the impact of HIV/AIDS on their families was an alternative to repaying their loved ones and to pursuing their moral selves in the cycle of reciprocity. Despite its inadequacy in fulfilling family obligations, such an attempt reflects individuals' efforts to prioritise family interests and exercise their own autonomy as a means of managing their feelings about themselves and their relationships to desired social norms. ${ }^{(21)}$
In conclusion, family played an important role in shaping the experiences of the HIV-infected individuals in this study, especially when other sources of support were unavailable or hard to access in their socioeconomic environment. These individuals' understanding of family obligations and their ability to fulfil the reciprocal duties among family members had influenced their decision-making on disclosure, demanding family support, making sense of and reconstructing family relationships, and developing strategies to minimise the impact of this disease on their loved ones. Echoing the results of earlier research, ${ }^{(22)}$ this study reveals that HIV/AIDS has posed two major challenges for families in China affected by it: First, AIDS stigma applies not only to HIV-positive individuals, but also to their families; second, an infected individual increases the financial and care burdens borne by, and compromises the welfare of, that individual's family.

In a society in which family still plays an important role in social support and social welfare provision, HIV infection can never be merely an individual matter, but rather is a family concern that profoundly shapes the lives of every member. The development of HIV/AIDS interventions in China must therefore take into account the importance of family support and the overall effects of the disease on family welfare. By seeing the family from the perspectives of HIV-infected individuals, moreover, this study has discovered that these individuals' well-being is shaped not only by the family support available to them, but also by their own perceptions of their performance in the cycle of reciprocal duties within the family. Far from being solely "victims" of this disease, these individuals were active in managing stigma and guilt, and in exercising their ability to contribute to family, and had a strong intention to pursue their moral self in spite of the difficulties in their lives.

Recognising their aspiration to fulfil family obligations is an important aspect of developing more sensitive services that can help these individuals make decisions and changes that will be beneficial to themselves and their families. Yet it is similarly important to recognise that both family support and individual autonomy may be unsustainable in view of expected variations in the capacity to mobilise and access social

20. Eleanor E. Holroyd, "A Cultural Model Approach," art. cit.; Eleanor E. Holroyd, "Chinese Cultural Influences," art. cit.

21. Evring Goffman, Stigma: Note on the Management of Spoiled Identity, Englewood Cliffs, Prentice-Hall Inc., 1963.

22. For example, see Li Li et al., "Understanding Family Support," art. cit.; Li Li et al., "Stigmatization and Shame," art. cit.; Jun-qing Wu et al., "Family Status and Dilemma," art. cit:; Lawrence Hsin Yang et al., "'Face' and the Embodiment of Stigma in China," art. cit. 
capital and economic resources. Individuals living in poverty, for instance, may find that HIV infection generates a more urgent need for economic survival than for family support. ${ }^{(23)}$ Likewise, the patriarchal order permeating the norm of family obligation may result in feminisation of caregiving within the family, and reinforce the inequality experienced by HIV infected women and affected female family members. ${ }^{(24)}$ Changes in social and macro-structural conditions (e.g., social stigma, gender imparity, welfare policy, and systematic inequality) are also prerequisites for families playing a constructive and sustainable role in improving HIV-infected individuals' quality of life and well-being. While fully appreciating the indispensable role of family in helping these individuals cope with the disease, however, this study suggests that when it comes to confronting such major health risks as HIV/AIDS, the family is not, and should not be, a primary or sole source of support for infected individuals, and that more sustainable assistances at an institutional level should be advocated and developed.

It should also be noted that just as people and families affected by HIV/AIDS are not a homogeneous group, neither are their experiences with the disease. The small sample size also limits this article in some ways: For instance, the results of this study might not be generally applicable to all affected individuals and families in China. Given the insufficiency of information in this field, there is nevertheless little doubt that this exploratory study contributes to our understanding of the interactions between HIV/AIDS and the notion of family obligation in the Chinese context. Such knowledge will also help us understand the impact of the AIDS epidemic on families in China, and contribute to developing responsive programs and policies that will increase the capacity of affected individuals and families to collectively and collaboratively respond to this disease. ${ }^{\bullet}$ 